\title{
HTLV-1 epigenetic modification of the FoxP3 TSDR in HAM/TSP decreases the functional proliferative suppression of Tregs
}

\author{
Monique R Anderson ${ }^{1,2^{*}}$, Yoshimi Akahata', Raya Massoud ${ }^{1}$, Nyater Ngouth', Unsong Oh ${ }^{3}$, Steven Jacobson ${ }^{1}$ \\ From 16th International Conference on Human Retroviruses: HTLV and Related Viruses \\ Montreal, Canada. 26-30 June 2013
}

HTLV-1 is a human retrovirus that is associated with adult T-cell leukemia/ lymphoma (ATLL) as well as the neuroinflammatory disorder HTLV-1 associated myelopathy/ tropical spastic paraparesis (HAM/TSP). In these patients, HTLV-1 is primarily found in the CD4+CD25+ T cell subset (Regulatory $\mathrm{T}$ cells or Tregs), the cells that are responsible for peripheral immune tolerance and which are known to be dysfunctional in HAM/TSP. However, due to the inherent inflammatory component of HAM/ TSP, markers normally used to characterize $\mathrm{T}$ regs, such as CD25, FoxP3, and CTLA4 are problematic in differentiating Tregs. Recent evidence has shown that FoxP3 expression and function is determined epigenetically, specifically through DNA methylation in the Treg-specific methylation region (TSDR). To more precisely characterize Treg cells, we analyzed the methylation status of specific CpGs in the TSDR in PBMCs, CD4+ T cells, and $\mathrm{CD} 4+\mathrm{CD} 25+\mathrm{T}$ cells from normal healthy donors (NDs) and HAM/TSP patients. We demonstrated that there is decreased demethylation in PBMCs and CD4+CD25+ $\mathrm{T}$ cells from HAM/TSP patients as compared to NDs, despite the increased CD4+CD25+ frequency in HAM/ TSP. Further, decreased TSDR demethylation correlates with decreased functional suppression in Treg cells of HAM/TSP patients. Additionally, increased HTLV-1 tax expression in PBMC culture correlates with this decrease in FoxP3 TSDR demethylation. Overall, we suggest that HTLV-1 infection decreases Treg functional suppressive capacity in HAM/TSP through epigenetic modification within the FoxP3 locus and that this dysregulation

\footnotetext{
* Correspondence: andersonmr2@mail.nih.gov

'Neuroimmunology Branch, Viral Immunological Section, National Institutes for Neurological Diseases and Stroke, National Institutes of Health, Bethesda, MD, USA

Full list of author information is available at the end of the article
}

of Treg function may contribute to HAM/TSP disease pathogenesis.

\section{Authors' details}

${ }^{1}$ Neuroimmunology Branch, Viral Immunological Section, National Institutes for Neurological Diseases and Stroke, National Institutes of Health, Bethesda, MD, USA. ${ }^{2}$ Howard Hughes Medical Institute- National Institutes of Health Research Scholars Program, Howard Hughes Medical Institute. Chevy Chase, MD, USA. ${ }^{3}$ Department of Neurology, Virginia Commenwealth University. Richmond, VA, USA.

Published: 7 January 2014

\section{doi:10.1186/1742-4690-11-S1-034}

Cite this article as: Anderson et al: HTLV-1 epigenetic modification of the FoxP3 TSDR in HAM/TSP decreases the functional proliferative suppression of Tregs. Retrovirology 2014 11(Suppl 1):034.

\section{Submit your next manuscript to BioMed Central and take full advantage of: \\ - Convenient online submission \\ - Thorough peer review \\ - No space constraints or color figure charges \\ - Immediate publication on acceptance \\ - Inclusion in PubMed, CAS, Scopus and Google Scholar \\ - Research which is freely available for redistribution

